\title{
Conceito Jurídico de Software, Padrão Proprietário e Livre: Políticas Públicas ${ }^{1}$
}

\section{Software Legal Concept, Proprietary and Free Standard: Public Policies}

\author{
Luiz Otávio Pimentel
}

Universidade Federal de Santa Catarina, Florianópolis, SC, Brasil

\section{Cláudio Eduardo Regis de Figueiredo e Silva}

Escola Superior de Magistratura de Santa Catarina, Florianópolis, SC, Brasil

\begin{abstract}
Resumo: Este trabalho faz uma análise dos principais direitos de propriedade intelectual de software e de padrões de software, apontando diferenças entre o proprietário e o livre, fazendo referência às políticas públicas de inovação no Brasil. Traz a revisão conceitual das principais características e dos efeitos jurídicos da opção pela utilização de software e padrão proprietários, software e padrão livre. Considera-se que a abordagem jurídica é distinta conforme a destinação dos bens, seja insumo para a produção de outros bens e para a prestação de serviço ou para o consumo dos bens que utilizam algum tipo de programa de computador e padrão relacionado. A abordagem, neste artigo, é voltada para o software como insumo e para utilização empresarial ou pelo setor público.
\end{abstract}

Palavras-chave: Direito de Propriedade Intelectual. Software. Padrões. Brasil.

\begin{abstract}
This paper analyses the main aspects of computer programs intellectual property rights, with focus on the differences between free and proprietary software and the policies for innovation in Brazil. It contains a conceptual review of the main characteristics and legal effects of proprietary and free software. It is considered that the legal protection is distinct according to the destination of goods, as capital goods, in which computer programs work as inputs for the production of other goods and the provision of services, or as consumer goods, normally intended for final use or consumption. This paper approaches software as a capital good in businesses and as an input for providing public services.
\end{abstract}

Keywords: Intellectual Property Law. Software. Standard. Brazil.

\footnotetext{
${ }^{1}$ Recebido em: 03/02/2014

Revisado em: 15/03/2014

Aprovado em: 19/05/2014
} 


\section{Introdução ao Tema}

Serão analisados neste artigo os principais direitos de propriedade intelectual de software e de padrões de software apontando diferenças entre o proprietário e o livre, fazendo referência às políticas públicas de inovação no Brasil. $\mathrm{O}$ assunto não é novo.

Os debates sobre a propriedade intelectual de programas de computador na ordem jurídica internacional foram intensos, a partir das negociações do que viria a ser o Acordo sobre os Aspectos dos Direitos de Propriedade Intelectual relacionados com o Comércio da Organização Mundial do Comércio (OMC). Acordo conhecido pela sigla em inglês TRIPS, durante e após a Rodada Uruguai do GATT (1986-1994). Outra onda de debates ocorreu a partir de 1994, quando os estados iniciaram a internalização do TRIPS nos ordenamentos internos.

No Brasil, o assunto entrou na agenda de algumas políticas públicas quando o movimento do software livre e aberto cresceu, suscitando amplos debates jurídicos, que culminam com a chegada ao Supremo Tribunal Federal de medida cautelar em ação direta de inconstitucionalidade de lei estadual, referida no final deste artigo.

Recentemente, alguns países da América Latina passaram a discutir premissas para o estabelecimento de políticas públicas e leis determinando preferência para o software livre nas compras e serviços do setor público. Ao invés de utilizar o poder de compras do governo, ou investimento de recursos em pesquisa e desenvolvimento (P\&D), elas tentam encontrar alternativas para poupar os recursos públicos e diminuir os custos de utilização de licenças de software proprietário. Outras vezes, buscam alternativas para estimular o desenvolvimento de software local e novos serviços de baixo custo sem avaliar previamente os impactos na qualidade, possibilidade de maior agregação de valor e segurança dos resultados. E, outras vezes, aparecem alternativas de open source.

Observa-se que quase sempre há uma grande confusão entre o significado jurídico de software proprietário e software livre, que acaba tendo por efeito, no sistema econômico e financeiro, muitas vezes, mais gas- 
tos públicos com o uso de software livre, que requer serviços cada vez mais sofisticados por força da opção por essa alternativa.

Além disso, muitos países impõem ao serviço público programas de computador que não são eficientes, de difícil operação, manutenção onerosa e custos de serviço muito mais elevados que aqueles de software de mercado ou desenvolvidos por encomenda. O resultado acaba sendo mais imposição aos contribuintes e ineficiência dos serviços oferecidos aos cidadãos.

Outro tema tangente, que se procura esclarecer, são as distinções entre os padrões proprietários e livres, vinculados à interoperabilidade, relacionados a protocolos que cumpram certos requisitos, todavia não acordados globalmente, por exemplo: a avaliação pública para que possam ser usados sem restrição; auditoria técnica de cumprimento de requisitos de utilização; a necessidade de utilização de componentes ou extensões adicionais; que estejam livres de cláusulas legais ou técnicas que limitem a sua utilização em algum modelo de negócio; que possam ser desenvolvidos ou aperfeiçoados por outra empresa; que estejam disponíveis como uma solução completa para todos os interessados. Também se fará referência aos formatos proprietários e abertos, que são especificações para o armazenamento digital de dados, em quanto um subconjunto dos padrões.

Os aspectos jurídicos que podem ser regulados, cujas principais alternativas devem ser bem conhecidas, contam com dois grupos principais de defensores e de conjuntos de normas aplicáveis: um que reúne o movimento pelos padrões e formatos livres ou abertos, protegidos pela via contratual em rede; e, outra dos potenciais titulares de direitos de padrões e formatos proprietários ou fechados, protegidos por direitos de propriedade e cláusulas de contratos.

Muitos países têm políticas públicas que incentivam e promovem a inovação, incluindo a tecnologia da informação e comunicação. Alguns o fazem para incentivar o uso de padrões livres ou abertos tentando forçar o seu uso na troca, transmissão, armazenamento e processamento eletrônico de dados, informações e documentos do setor público nacional (a nação, estados da federação, províncias, municípios, ou empresas públi- 
cas); ou para alcançar a soberania tecnológica e o acesso dos cidadãos à informação pública com software livre ou aberto de forma obrigatória. $\mathrm{O}$ que significa, em matéria de compras e contratos públicos, favorecimento a certas empresas e distorção da livre concorrência.

Além disso, há problemas de segurança, confidencialidade e privacidade dos dados e informações operados nos sistemas livres, que nem sempre possibilitam a reparação dos danos.

Nos estados nacionais, como o Brasil, a ordem econômica é fundada na valorização do trabalho humano e na livre iniciativa, balizada, entre outros, pelos princípios da propriedade privada, da função social da propriedade, da livre concorrência e da defesa do consumidor, segundo a Constituição Federal, artigo 170, incisos II, III, IV, V. (BRASIL, 1988)

Considerando a quantidade de empresas que existem no mercado e a concorrência entre elas, a propriedade intelectual tem papel importante porque disciplina a utilização de ativos intangíveis capazes de diferenciarem produtos e serviços.

O conceito jurídico de propriedade intelectual de tecnologias utilizadas no tratamento de dados e informações tem relevância na economia, nos negócios e nas políticas públicas.

A expressão "conceito jurídico" indica o sentido, a significação e a interpretação, que se tem a respeito das coisas, dos fatos e das palavras como aquilo que é regular, que é legal, que é conforme ao Direito, como ordenamento das relações sociais, econômicas, políticas e de instituição dos direitos, seja no âmbito nacional, seja no âmbito internacional. (SILVA, 2013)

Nesse sentido, trata-se neste artigo dos conceitos jurídicos positivos de software e padrão proprietário, software e padrão livre, e de algumas das implicações desses assuntos na segurança de dados e informações públicas.

O padrão é expresso aqui como tipo, modelo ou modelo-tipo legal de pesos e medidas (FERREIRA, 2010). Padrão é sinônimo de uniformidade, segurança na produção e nos serviços; não existem no mundo 
padrões únicos, e sim padrões mais ou menos utilizados em certos períodos ou setores industriais e de serviços. Uma organização internacional, um país ou bloco de países, uma associação de normas técnicas, uma empresa ou um acordo empresarial entre fornecedores e distribuidores pode, por exemplo, instituir, recomendar ou adotar o seu próprio padrão técnico para a produção, distribuição ou prestação de serviços.

Neste texto serão revisados as principais características e os efeitos jurídicos da opção pela utilização de software e padrão proprietários, software e padrão livre, fazendo referência às políticas públicas.

Considera-se que a abordagem jurídica é distinta conforme a destinação dos bens, seja insumo para a produção de outros bens e para a prestação de serviço, ou para o consumo dos bens que utilizam algum tipo de programa de comutador e padrão relacionado. Nossa abordagem, neste artigo, é voltada para o software como insumo e para utilização empresarial ou pelo setor público.

Inicia-se revendo o conceito jurídico de propriedade.

\section{Conceito de Direito de Propriedade}

A origem do direito positivo de propriedade remonta ao direito romano. A definição do substantivo "propriedade" não teve mudanças significativas ao longo dos tempos. Sendo entendida socialmente como a relação que se estabelece entre um sujeito específico e um objeto específico que lhe pertence com exclusividade, em oposição ao universo de outras pessoas e objetos existentes. O sujeito de direitos pode ser público ou privado, singular ou coletivo, uma unidade ou um grupo de pessoas. $\mathrm{O}$ objeto de direito de propriedade pode ser material ou imaterial, uma unidade ou grupo de unidades. Diz-se que o proprietário é o sujeito dos direitos de propriedade. (BOBBIO; MATTEUCCI; PASQUINO, 2004)

A propriedade é um direito real sobre a coisa que independe de prestação de qualquer pessoa para o seu exercício, que pertence com exclusividade à determinada pessoa física ou jurídica, pública ou privada. Tradicionalmente tem três características marcadas por restrições legais e 
condicionantes sociais: o absolutismo, porque é oponível perante todos; a exclusividade do domínio; e a perpetuidade, no sentido de que a sua duração se estende pelo tempo que lhe assegurar a lei.

Segundo o Código Civil Brasileiro, Lei n. 10.406, artigo 1.228, caput, propriedade é a faculdade que tem o proprietário de usar, gozar e dispor da coisa que integra o seu patrimônio, e o direito de reavê-la do poder de quem quer que injustamente a possua ou detenha. (BRASIL, 2002)

Coisa, no Direito Civil, indica os objetos suscetíveis de direitos, tudo que pode ou possa servir de utilidade para as pessoas, podendo ser material ou imaterial, também sinônimo de bem. O conjunto dos bens de uma pessoa é designado por patrimônio.

O direito real sobre a coisa, que só existe juridicamente se definido pela lei, se distingue do direito obrigacional, que regula as relações jurídicas transitórias que unem pessoas em torno de prestação econômica, positiva ou negativa, de dar, fazer ou não fazer. O direito obrigacional é um direito relativo, porque a prestação que é seu objeto somente pode ser exigida entre as partes ou sujeitos de relação jurídica instituída. Seu principal efeito é tornar obrigatória uma ou mais prestações de pessoa com base na autonomia privada, sem depender de previsão legal prévia e dentro dos limites da autonomia da vontade, por isso, teoricamente caracterizada como infinita.

Cabe recordar que a propriedade é considerada um dos direitos fundamentais. A Declaração Universal dos Direitos Humanos, no artigo XVII, proclama que "[...] toda pessoa tem direito à propriedade, só ou em sociedade com outros [...]" e que "[...] ninguém será arbitrariamente privado de sua propriedade". (ONU, 1948, art. XVII)

O mesmo pode ser observado nas constituições dos estados nacionais. A Constituição Federal do Brasil, por exemplo, no caput do artigo $5^{\circ}$, garante aos brasileiros e aos estrangeiros residentes no país a inviolabilidade do direito à propriedade. (BRASIL, 1988, art. $5^{\circ}$ )

No Brasil, a Constituição Federal, ainda no caput do artigo $5^{\circ}$, estabelece que todos são iguais perante a lei, sem distinção de qualquer espé- 
cie, garantido aos brasileiros e aos estrangeiros residentes no país a inviolabilidade dos direitos de propriedade. ${ }^{2}$

A seguir, trataremos do conceito jurídico de propriedade intelectual.

\section{Conceito Jurídico de Propriedade Intelectual}

A propriedade intelectual é o "[...] conjunto de princípios e de regras que regulam a aquisição, o uso, o exercício e a perda de direitos e de interesses sobre ativos intangíveis diferenciadores que são suscetíveis de utilização no comércio". Esse conjunto de direitos "[...] não cobre todos os ativos intangíveis, mas somente aqueles que servem de elementos de diferenciação entre concorrentes [...]" no mercado. (CARVALHO, 2009, p. 23-26)

Os direitos de propriedade intelectual protegem os resultados da atividade criativa e inventiva e, também, signos distintivos como as indicações geográficas, a reputação dos comerciantes e as marcas que são importantes elementos de diferenciação. (CARVALHO, 2009, p. 23-26)

Os direitos de propriedade intelectual abrangem dois grandes campos, a propriedade industrial e o direito autoral, cuja diferença entre esses direitos reside nos respectivos objetos de proteção e na característica dos direitos concedidos.

Os direitos de propriedade industrial incidem sobre ideias, enquanto os direitos autorais incidem sobre expressões, comportando várias exceções. Os direitos de propriedade industrial pró́bem que terceiros utilizem os ativos protegidos. Os direitos autorais proíbem que terceiros copiem, ou que pratiquem os diversos atos que constituem modalidades de cópia, como reproduzir, traduzir, adaptar, comunicar, transmitir e fixar as obras protegidas. Sendo importante observar que a Convenção de Berna, expressando uma dimensão positiva dos direitos autorais, autoriza a pratica dos atos exclusivos que enumera. (CARVALHO, 2009, p. 23-26)

2 No mesmo sentido, a Constituição nacional argentina, artigo 14, artigo 20 (ARGENTINA, 1994); Constituição chilena, artigo 19, incisos $24^{\circ}$ e $25^{\circ}$ (CHILE, 2005); Constituição colombiana, artigo 58, artigo 100 (COLÔMBIA, 1991). 
A propriedade industrial cobre três âmbitos parcialmente sobrepostos: as criações técnicas, como patentes, modelos de utilidade, cultivares, topografias de circuitos integrados, desenhos industriais; alguns signos distintivos, como os sinais distintivos de marcas de produtos, serviços, coletivas e de certificação, nomes comerciais, títulos de estabelecimento, insígnias e indicações geográficas; e, vantagens competitivas não proprietárias, como a repressão da concorrência desleal, que envolve os segredos, dados de testes e outros elementos do fundo de comércio, que envolvem a reputação, a clientela e o trade dress. (CARVALHO, 2009, p. 23-26)

São exemplos de sobreposição parcial dos direitos protegidos dentro da propriedade industrial: o trade dress que não é proprietário, mas constitui um sinal distintivo; os desenhos industriais que são as criações geralmente técnicas, mas também podem ser sinais distintivos por vezes registrados como marcas. (CARVALHO, 2009, p. 23-26)

São exemplos de sobreposição parcial entre os direitos de propriedade industrial e autorais: os desenhos industriais, que podem ser protegidos pelo direito de autor; os programas de computador, que são designados pelo TRIPS e pelo WCT como objetos do direito de autor, mas podem ser patenteáveis; a proteção das cultivares e dos micro-organismos, que geram um direito muito semelhante ao do direito de autor ao proibir a reprodução do objeto de proteção. (CARVALHO, 2009, p. 23-26)

A propriedade intelectual, considerando a sua relação com o comércio mundial, está protegida internacionalmente por força do TRIPS. O objetivo do acordo foi alcançar padrões normativos adequados de proteção da propriedade intelectual em todos os países membros da OMC. ${ }^{3}$

O TRIPS tem um princípio básico, disposto na sua primeira parte, que se reveste de particular importância para o regime jurídico de proteção da propriedade intelectual, que é a não discriminação, ou seja, o tratamento nacional, que considera a igualdade de tratamento para nacionais e estrangeiros em sua aplicação. O princípio é fundamental, também,

3 TRIPS/OMC: A organização conta com 160 membros. Disponível em: <http://www. wto.org/>. Acesso em: 30 jan. 2014. 
em outros acordos internacionais de propriedade intelectual anteriores à OMC.

Na segunda parte do TRIPS estão dispostos diferentes tipos de direitos de propriedade intelectual e a forma de como protegê-los, partindo das obrigações para os membros dos acordos internacionais regidas pela Organização Mundial da Propriedade Intelectual (OMPI), como as convenções de Paris para a propriedade industrial e de Berna para os direitos autorais, aos quais o TRIPS acrescenta um número significativamente importante de normas. ${ }^{4}$

No âmbito nacional, por exemplo, a Constituição brasileira, artigo $5^{\circ}$, incisos XXII, XXIII, XXIV, XXVII, XXVIII e XXIX, garante o direito à propriedade intelectual, dispondo que pertencem aos autores $\mathrm{o}$ direito exclusivo de utilização, publicação ou reprodução de suas obras; que a lei assegura aos autores de inventos industriais privilégio temporário para sua utilização, bem como a proteção às criações industriais; que são garantidos, na lei, a proteção às participações individuais em obras coletivas, bem como o direito dos criadores e dos respectivos sindicatos e associações para fiscalizar a exploração econômica das obras que criarem ou nas quais participam; que a lei assegura aos autores de inventos industriais o privilégio temporário para sua utilização, bem como a proteção às criações industriais; tudo levando em consideração o interesse social e o desenvolvimento econômico do país. (BRASIL, 1998)

A seguir será tratado do conceito jurídico de software e de padrão técnico na propriedade intelectual.

4 OMPI: organismo das Nações Unidas, conta com 186 membros. Disponível em: $<$ http://www.wipo.int/>. Acesso em: 30 jan. 2014.

5 No mesmo sentido: Constituição nacional argentina, artigo 17 (ARGENTINA, 1994); Constituição chilena (CHILE, 2005); Constituição colombiana, artigo 61 (COLÔMBIA, 1991). 


\section{Conceito Jurídico de Software e Padrão Proprietário}

O atual modelo, a extensão e o alcance da proteção da propriedade intelectual do software necessitam ser revisados internacionalmente após 20 anos do TRIPS, mas não é o foco deste artigo.

Houve razões importantes para a escolha da proteção do software, sentido amplo, pelo regime jurídico dos direitos autorais. Destacando-se que os programas de computador, em sentido estrito, foram considerados basicamente como escritos e, nos termos do artigo 2(1) da Convenção de Berna, a finalidade para a qual os escritos são criados é irrelevante do ponto de vista da sua qualificação como obras literárias, se eles são criações intelectuais originais. (WIPO, 2008, p. 435-442) ${ }^{6}$

Embora os programas de computador como expressões literais possam ser protegidos por direitos de autor, se as ideias contidas nos programas de computador incluem características técnicas aportando soluções técnicas, então a expressão dessas ideias pode ser patenteável.

O TRIPS, artigo 27(1), dispõe que são patenteáveis todos os domínios da tecnologia, desde que sejam novos, envolvam uma atividade inventiva e sejam susceptíveis de aplicação industrial, sujeito a certas exceções limitadas. (OMC, 1994)

Essa ampla possibilidade de patenteabilidade pelo TRIPS provocou uma discussão sobre o assunto no sentido de onde traçar a linha divisória entre os direitos autorais e a proteção de patentes para programas de computador.

Em alguns países, as invenções relacionadas com software são patenteáveis se tiverem um caráter técnico (technical character) ou envolverem função técnica (technical teaching), isto é, uma instrução dirigida a uma pessoa especialista na matéria sobre como resolver um problema técnico específico usando determinados meios técnicos.

\footnotetext{
6 Convenção de Berna de 1886, revisada em Paris, 1896, Berlim, 1908, Berna, 1914, Roma, 1928, Bruxelas, 1948, Estocolmo, 1967, e Paris, 1971, alterada em 1979 (OMPI). Podem aderir à Convenção todos os estados. Sobre o assunto ver: Ascensão (1997) e Correa (1996).
} 
Logo, as invenções relacionadas com programa de computador devem ter um efeito técnico para receber proteção por patente. Assim, se o software produz um efeito técnico, é necessário, então, examinar se estão preenchidos os demais requisitos de patenteabilidade.

Os programas de computador, incluindo padrões, em código objeto compartilham o status formal de direito autoral de outras obras literárias, artísticas ou científicas armazenadas em sistemas de computador em forma legível por máquina. Enquanto eles são ininteligíveis em código objeto, que pode ser recuperado - "descompilado" - em forma de código-fonte de onde eles são inteligíveis. ${ }^{7}$

É reconhecido que todas as categorias de objetos estão protegidos contra o armazenamento não autorizado pelo titular de direitos na forma digital, porque tal armazenamento é uma reprodução. Nesse aspecto, não importa de que, por exemplo, uma obra cinematográfica possa não ser percebida diretamente a partir de um DVD, mas somente depois de uma "descompilação" que ocorreu em um DVD-player.

O pré-requisito normal para a proteção de direitos autorais, que estabelece que uma obra deva ser original, é razoavelmente adequado para ser aplicado a programas de computador. ${ }^{8}$

Embora a maioria dos programas de computador consista de elementos rotineiros que, muitas vezes, por si só dificilmente se qualificam como obras originais, a combinação de tais elementos e a estruturação dos programas - com a exceção de alguns programas muito simples - os torna suficientemente criativos e protegidos pelo Direito.

Ideias e métodos abstratos para resolver problemas, os chamados "algoritmos", não são protegidos por direitos de autor, o que limita a proteção à expressão de tais ideias e algoritmos, mas essa é uma consequência da proteção pelos direitos autorais, porque uma proteção adequada é

7 Descompilador: é um programa de computador que transforma código objeto em código fonte; traduz código de máquina ou programa executável em código fonte.

8 Segundo a Lei n. 9.610, artigo $5^{\circ}$, VIII, f, considera-se obra "originária a criação primígena". (BRASIL, 1998) 
oferecida, sem criar obstáculos injustificados à criação independente de outros programas.

Um argumento recorrente sobre o prazo de proteção de obras literárias, de 50 anos após a morte do autor nos termos da Convenção de Berna, que é muito longo em relação aos programas de computador, pois esses programas geralmente tornam-se desatualizados em um tempo mais curto.

O mesmo argumento, do tempo de proteção de 50 anos, se aplica a várias outras categorias de obras literárias, científicas e artísticas. A realidade é que, se uma obra é obsoleta, não vai ser usada e, portanto, a proteção também não será invocada. O termo do prazo ao amparo da Convenção de Berna deve ser considerado nada mais do que um limite superior para as obras que realmente permanecerem de interesse dos usuários e no comércio por mais tempo.

O TRIPS estabelece que os programas de computador sejam protegidos como obras literárias pela Convenção de Berna e dispõe como deverão ser protegidas as bases de dados. Ampliando as normas internacionais para abarcar os direitos de locação e de proibição da locação comercial ao público de suas obras, a fim de evitar que uma realização muito generalizada de cópias pudesse afetar as receitas que poderiam obter os titulares de direitos.

O consenso internacional em matéria de proteção de direitos de autor de programas de computador se reflete em dois tratados internacionais, especialmente o artigo 10(1) do Acordo TRIPS e o artigo 4 do Tratado de Direitos Autorais da OMPI (WCT). ${ }^{9}$

Embora com texto diverso, essas duas disposições prescrevem que os programas de computador devem ser protegidos como obras literárias, e que a proteção deve ser a mesma que a concedida a essas obras ao am-

\footnotetext{
9 WCT: Article 4, Computer programs are protected as literary works within the meaning of Article 2 of the Berne Convention. Such protection applies to computer programs, whatever may be the mode or form of their expression. [3] Agreed statement concerning Article 4: The scope of protection for computer programs under Article 4 of this Treaty, read with Article 2, is consistent with Article 2 of the Berne Convention and on a par with the relevant provisions of the TRIPS Agreement. (OMPI, 1996)
} 
paro da Convenção de Berna. Isso não exclui que as leis nacionais possam classificar os programas de computador como uma categoria separada de obras, desde que o nível de proteção não seja menor do que o concedido às obras literárias pela Convenção.

O Acordo TRIPS também esclarece que a proteção aplica-se aos programas de computador "em código fonte ou objeto", enquanto o WCT expressa o mesmo de uma forma mais ampla: "essa proteção aplica-se aos programas de computador, qualquer que seja o modo ou forma de expressão".

A Convenção de Berna ${ }^{10}$ se funda em três princípios básicos e contém disposições que determinam a proteção mínima que há de se conferir às obras, assim como as disposições especiais para os países em desenvolvimento que fizeram reservas para valer-se delas.

Segundo o princípio do trato nacional, os autores gozam, no que concerne às obras protegidas por força da Convenção de Berna, nos países da União, exceto o de origem da obra, dos direitos que as respectivas leis concedem atualmente ou venham a conceder no futuro aos nacionais, assim como dos direitos especialmente concedidos pela Convenção. A proteção no país de origem é regulada pela legislação nacional. Entretanto, quando o autor não pertence ao país de origem da obra quanto à qual é protegido pela Convenção, ele terá, nesse país, os mesmo direitos que os autores nacionais - Convenção de Berna: artigo 5(1,3). (OMPI, 1979)

Segundo o princípio da proteção automática, o exercício dos direitos autorais não está subordinado a qualquer formalidade - Convenção de Berna: artigo 5(2). (OMPI, 1979)

Segundo o princípio da independência da proteção, o exercício dos direitos autorais independe da existência da proteção no país de origem das obras. Por conseguinte, afora as estipulações da Convenção de Berna, a extensão da proteção e os meios processuais garantidos ao autor para salvaguardar os seus direitos regulam-se exclusivamente pela legislação

${ }_{10}$ Decreto n. 75.699, de 6 de maio de 1975, promulga a Convenção de Berna para a Proteção das Obras Literárias e Artísticas, de 9 de setembro de 1886, revista em Paris, a 24 de julho de 1971. (BRASIL, 1975) 
do país onde a proteção é reclamada - Convenção de Berna: artigo 5(2). $(\text { OMPI, 1979) })^{11}$

As condições mínimas de proteção jurídica da Convenção de Berna se referem às obras e aos direitos protegidos, bem como a sua duração, como se pode observar: em relação às obras, a proteção deve incluir todas as produções do domínio literário, científico e artístico, qualquer que seja o modo ou forma de expressão; devem ser reconhecidos como exclusivos de autorização do titular os direitos de traduzir e de fazer adaptações da obra; no que respeita à duração da proteção, a regra geral é que a proteção deve ser concedida por um período de 50 anos após a morte do autor Convenção de Berna: artigo 2(1). (OMPI, 1979)

A Convenção de Berna permite certas limitações e exceções em matéria de direitos econômicos, ou seja, nos restritos casos em que obras protegidas possam ser utilizadas sem a autorização do proprietário dos direitos autorais e sem pagar uma compensação.

Geralmente se utiliza o termo "uso gratuito" de obras protegidas para se referir a essas limitações: reprodução em certos casos especiais, citações e utilização de obras a título de ilustração no ensino, reprodução de artigos de jornais ou similares, a utilização de obras para obter informações sobre eventos atuais, e gravações efémeras com fins de radiodifusão - Convenção de Berna: artigos 9(2), 10, 10 bis, 11(3). (OMPI, 1979)

No Anexo da Revisão de Paris da Convenção de Berna se permitiu aos países em desenvolvimento implementar licenças compulsórias para a tradução e reprodução de obras em certos casos, no contexto de atividades de aprendizagem. Nesses casos, é permitido o uso descrito sem a autorização do titular do direito ficando sujeito ao pagamento de uma remuneração a ser estabelecida por lei.

O tratado formalizado no âmbito da OMPI sobre direito de autor, o WCT, é um acordo especial adotado ao abrigo da Convenção de Berna. O Brasil não é parte; entre os Estados sul-americanos a Argentina, Chile e

11 Entretanto, se num país da União se prevê um prazo mais longo de proteção que o mínimo prescrito pela Convenção, e chega a termo a proteção da obra no país de origem, a proteção poderá negar-se porque tenha terminado no país de origem. (OMPI, 1979) 
Colômbia o ratificaram.12 Embora isso não seja exigido pelo tratado, as partes contratantes no acordo devem respeitar as disposições substantivas da revisão de Paris da Convenção de Berna. (OMPI, 1971)

O tratado inclui expressamente como objetos de proteção pelos direitos autorais: os programas de computador, independentemente do seu modo ou forma de expressão; e a base de dados, compilações de dados ou outros materiais em qualquer forma, que em razão da seleção ou da disposição de seu conteúdo, constituam criações intelectuais. Quando a base de dados não constitui uma criação dessa natureza, está fora do âmbito do WTC.

Quanto aos direitos dos titulares, o WTC abrange três direitos: de distribuição, de aluguel e de comunicação ao público. Cada um deles constitui um direito exclusivo, sujeito a certas limitações e exceções.

Segundo o WCT, o direito de distribuição implica na autorização prévia do titular dos direitos antes da colocação à disposição do público do original ou cópias da obra mediante venda ou outro modo de licença.

Determina o WCT que o direito de aluguel implica na autorização prévia do titular dos direitos antes da locação comercial ao público do original ou cópias de programas de computador, exceto quando o programa em si não é o objeto essencial do aluguel.

Dispõe ainda o WCT, que o direito de comunicação ao público implica na autorização prévia do titular dos direitos antes de qualquer comunicação ao público por fio ou sem fio, incluindo a colocação ao alcance do público das suas obras, de tal forma que ele possa acessar essas obras a partir de um lugar e no momento por eles escolhido individualmente. Abrange especialmente a comunicação interativa e mediante prévia solicitação por internet.

O WCT incorpora a prova do critério triplo para determinação das limitações e exceções ao abrigo das disposições da Convenção de Berna, que estende a sua aplicação a todos os direitos. Nas declarações acordadas que acompanham o WCT se estipula que essas limitações e exceções

12 O WCT (OMPI, 1996) entrou em vigor em 2002. 
na legislação nacional de conformidade com a Convenção de Berna, podem ser extensivas para o ambiente digital. Os países podem formular novas exceções e limitações apropriadas para o ambiente digital. Permite-se a ampliação das limitações e exceções, ou a criação de outras novas, desde que se cumpram as condições da prova do critério triplo ou dos três passos. ${ }^{13}$

O WCT obriga as partes contratantes a prever recursos jurídicos que permitam evitar os atos dirigidos a neutralizar as medidas técnicas de proteção, como a criptografia, de que se valem os autores em relação com o exercício de seus direitos e evitar assim mesmo a supressão ou modificação de informação, tais como certos dados que identificam as obras ou seus autores, a qual é necessária para a gestão de seus direitos, como a concessão de licenças e a arrecadação e distribuição dos royalties.

Pelo WCT os estados contratantes são obrigados a adotar, de conformidade com seu ordenamento jurídico, as medidas necessárias para garantir a sua aplicação. Em particular, devem os países incluir na legislação nacional procedimentos de observância que permitam adotar medidas eficazes contra os atos de infração dos direitos previstos no tratado. Essas medidas deverão incluir recursos ágeis para evitar as infrações, assim como outros recursos que constituam um meio eficaz de dissuasão para novas infrações, o mesmo que é previsto no TRIPS.

No Brasil, por exemplo, a lei dos direitos autorais indica que são obras intelectuais protegidas as criações do espírito, expressas por qualquer meio ou fixadas em qualquer suporte, tangível ou intangível, conhecido ou que se invente no futuro, como os programas de computador, que são objeto de legislação específica, desde que observadas as disposições que lhes sejam aplicáveis pela lei dos direitos autorais. (BRASIL, 1998, art. $7^{\circ}$, inciso XII, $\S 1^{\circ}$ )

A lei brasileira dos direitos autorais inclui importantes conceitos jurídicos, considera: "distribuição" a colocação à disposição do público do

13 WCT (OMPI, 1996), artigo 10. Convenção de Berna, artigo 9(2). Podem ser autorizadas exceções e limitações ao direito de autor: [1] certos casos especiais; [2] se não conflitar com a exploração comercial normal da obra e, [3] de não prejudicar injustificadamente os interesses legítimos do autor (OMPI, 1979). Ver Basso (2007, p. 493-503). 
original ou cópia de obras, mediante a venda, locação ou qualquer outra forma de transferência de propriedade ou posse; "comunicação ao público" o ato mediante o qual a obra é colocada ao alcance do público, por qualquer meio ou procedimento que não consista na distribuição de exemplares; "reprodução" a cópia de um ou vários exemplares de uma obra, de qualquer forma tangível, incluindo qualquer armazenamento permanente ou temporário por meios eletrônicos ou qualquer outro meio de fixação; "obra em coautoria" quando é criada em comum, por dois ou mais autores; "obra originária" a criação primígena; "obra derivada", a obra que, constituindo criação intelectual nova, resulta da transformação de obra originária; "obra coletiva", a criada por iniciativa, organização e responsabilidade de uma pessoa física ou jurídica, que a publica sob seu nome ou marca e que é constituída pela participação de diferentes autores, cujas contribuições se fundem numa criação autônoma; "titular originário" o autor de obra intelectual; "contrafação" a reprodução não autorizada; "direitos patrimoniais do autor" o direito exclusivo de utilizar, fruir e dispor da obra literária, artística ou científica. (BRASIL, 1998, art. 50) $)^{14}$

No Brasil, por força do direito autoral, como previsto nos tratados internacionais, a utilização da obra, por quaisquer modalidades, depende de autorização prévia e expressa do autor, por exemplo a reprodução parcial ou integral, a edição, a adaptação e quaisquer outras transformações, a tradução para qualquer idioma, a distribuição, a utilização direta ou indireta da obra (empregando satélites artificiais, sistemas óticos, fios telefônicos ou não, cabos de qualquer tipo e meios de comunicação similares), a inclusão em base de dados, o armazenamento em computador, a microfilmagem e outras formas de arquivamento do gênero. (BRASIL, 1998, art. 29)

No caso da utilização de bases de dados, segundo os direitos autorais patrimoniais vigentes no Brasil, o titular terá o direito exclusivo, a respeito da forma de expressão da estrutura da referida base, de autorizar ou proibir: a sua reprodução total ou parcial, por qualquer meio ou processo; a sua tradução, adaptação, reordenação ou qualquer outra modificação, bem como a reprodução, distribuição ou comunicação ao público

14 Atualizado pela Lei n. 12.853 (BRASIL, 2013, art. 28). 
dessas operações; a distribuição do original ou cópias da base de dados ou a sua comunicação ao público. (BRASIL, 1998, art. 87)

No Brasil foram estabelecidas normas especiais para a proteção da propriedade intelectual de programa de computador e sua comercialização através da Lei n. 9.609/1998, que define programa de computador como

[...] a expressão de um conjunto organizado de instruções em linguagem natural ou codificada, contida em suporte físico de qualquer natureza, de emprego necessário em máquinas automáticas de tratamento da informação, dispositivos, instrumentos ou equipamentos periféricos, baseados em técnica digital ou análoga, para fazê-los funcionar de modo e para fins determinados. (BRASIL, 1998 , art. $1^{\circ}$ )

O regime jurídico brasileiro de propriedade intelectual de programa de computador é declaratório, porque independe de registro, e não inclui entre os direitos autorais as disposições relativas aos direitos morais, com ressalvas de difícil aplicação no caso de criações no âmbito empresarial. Os direitos atribuídos na lei são assegurados também aos estrangeiros domiciliados no exterior, desde que o país de origem do programa conceda aos brasileiros e estrangeiros domiciliados no Brasil direitos equivalentes. Estão incluídos o direito exclusivo de autorizar ou proibir o aluguel comercial, não sendo exaurível pela venda, licença ou outra forma de transferência da cópia do programa, salvo nos casos em que o programa em si não seja objeto essencial do aluguel. (BRASIL, 1998, art. $2^{\circ}$ )

O registro de programas de computador no Brasil pode ser realizado no Instituto Nacional da Propriedade Industrial (INPI), sendo necessário conter: os dados referentes ao autor e ao titular, se distinto do autor; a sua identificação e descrição funcional; e os trechos do programa e outros dados que se considerem suficientes para identificá-lo e caracterizar sua originalidade, ressalvando-se os direitos de terceiros e a responsabilidade 
do governo, com caráter sigiloso, não podendo ser reveladas, salvo por ordem judicial ou a pedido do próprio titular. (BRASIL, 1998, art. $\left.3^{\text {o }}\right)^{15}$

No que se refere à titularidade dos direitos de propriedade intelectual de programa de computador desenvolvido por empresa, no Brasil a regra é que pertencem com exclusividade ao empregador ou contratante de serviços, se for desenvolvido e elaborado durante a vigência de contrato de $\mathrm{P} \& \mathrm{D}$, ou se a atividade do empregado ou contratado de serviço seja prevista ou decorra da própria natureza dos encargos concernentes ao vínculo. Caso contrário, se o programa de computador foi criado sem relação com o contrato de trabalho ou prestação de serviços, e sem a utilização de recursos, informações tecnológicas, segredos industriais e de negócios, materiais, instalações ou equipamentos do empregador ou da empresa com a qual o empregador mantem contrato, pertencem ao seu criador. (BRASIL, 1998, art. $4^{\circ}$ )

Já no que diz respeito às derivações de programa de computador, os direitos sobre elas dependem da autorização ou estipulação contratual dada pelo titular dos direitos para a sua exploração econômica. ${ }^{16}$

15 Decreto n. 2.556 (BRASIL, 1998) regulamenta o registro previsto no artigo $3^{\circ}$ da Lei n. 9.609, que dispõe sobre a proteção da propriedade intelectual de programa de computador.

16 Lei n. 9.609, artigo $5^{\circ}$ (BRASIL, 1998). Lei n. 9.6010 (BRASIL, 1998), artigo 50, inciso VIII, alínea "g”, derivada é a obra que, constituindo criação intelectual nova, resulta da transformação de obra originária. Lei n. 9.279/1996: No direito de patente de invenção é prevista uma forma de derivação, que consiste no aperfeiçoamento ou desenvolvimento introduzido no objeto da invenção de matéria incluída no mesmo conceito inventivo; se protege por certificado de adição e pode ser requerido pelo depositante do pedido ou titular de patente de invenção (artigo 76); o certificado de adição é acessório da patente (artigo 77); o aperfeiçoamento introduzido em patente licenciada pertence a quem o fizer, sendo assegurado à outra parte contratante o direito de preferência para seu licenciamento (artigo 63); no caso de aperfeiçoamento realizado por empregado, na patente de titularidade do empregador, pode ser concedido a ele participação nos ganhos econômicos resultantes da exploração da patente (artigo 89). Lei n. 9.456/1997: sobre direitos de propriedade intelectual de cultivar, a proteção assegura a seu titular o direito à reprodução comercial, ficando vedados a terceiros, durante o prazo de proteção, a produção com fins comerciais, o oferecimento à venda ou a comercialização, do material de propagação da cultivar, sem sua autorização (artigo $9^{\circ}$ ); sempre que uma cultivar seja essencialmente derivada de uma 
O direito brasileiro não considera ofensa aos direitos do titular de programa de computador: (i) o backup ou cópia de salvaguarda de programa legitimamente licenciado; (ii) a citação parcial para fins didáticos; (iii) a semelhança com outro programa preexistente; (iv) a integração de um programa a um sistema aplicativo ou operacional, tecnicamente indispensável às necessidades do usuário, desde que para o uso exclusivo de quem a promoveu. (BRASIL, 1998, art. $6^{\circ}$ )

O regime jurídico brasileiro de propriedade intelectual de programa de computador estabelece garantias aos usuários de programa. Por isso, o contrato de licença de uso, o documento fiscal correspondente, os suportes físicos do programa ou as respectivas embalagens devem indicar o prazo de validade técnica da versão comercializada. Sendo obrigação de quem comercializa, no território nacional, durante o prazo de validade técnica da respectiva versão, assegurar aos usuários os serviços técnicos complementares relativos ao adequado funcionamento do programa, consideradas as suas especificações mesmo no caso de sua retirada de circulação comercial. (BRASIL, 1998, art. $7^{\circ}-8^{\circ}$ )

Nesse contexto é necessário definir o que significa usuário. A partir dos elementos centrais que definem o direito de propriedade - usar/utilizar, gozar/fruir e dispor - usuário é o titular do direito de uso. Considerando que o usuário é aquele que tem a faculdade de utilizar-se de coisa alheia, podendo dela retirar para si os frutos e proveitos. Logo, não alcança as duas outras faculdades da propriedade que são gozar/fruir e dispor. (SILVA, 2013)

O uso de programa de computador no Brasil pode ser objeto de contrato de licença, que pode ser comprovado pelo documento fiscal relativo ao negócio. (BRASIL, 1998, art. $9^{\circ}$ - 10)

A transferência de tecnologia de programa de computador, no Brasil, para que o contrato produza efeitos em relação a terceiros, deve ser registrada no INPI, cujo negócio deve incluir a entrega, por parte do fornecedor ao receptor da tecnologia, da documentação completa, em especial

cultivar protegida, sua exploração comercial estará condicionada à autorização do titular da proteção desta mesma cultivar protegida (artigo 10, $\S 2^{\circ}$, inciso II). 
do código-fonte comentado, memorial descritivo, especificações funcionais internas, diagramas, fluxogramas e outros dados técnicos necessários à absorção da tecnologia. (BRASIL, 1998, art. 11). ${ }^{17}$

Todos os direitos autorais e suas limitações se aplicam aos padrões técnicos que possam ser caracterizados como uma obra.

A seguir trataremos do conceito jurídico de software e padrão livre.

\section{Conceito Jurídico de Software e Padrão Livre}

Tratando dos direitos de propriedade intelectual de programa de computador, a diferença do software livre se refere ao exercício não exclusivo dos direitos do titular, constante da obrigação estabelecida no pacto de livre utilização (executar, estudar, adaptar, acessar o código-fonte, copiar) e de livre fruição (distribuir) do software.

Segundo a GNU, ${ }^{18}$ um programa de computador é "software livre" se os usuários possuem "liberdades essenciais" de acesso ao código-fonte do programa, de executar o programa para qualquer propósito, de estudar como o programa funciona, de adaptar o programa às necessidades do usuário, de redistribuir cópias do programa e de distribuir cópias de versões modificadas para terceiros. (O SISTEMA OPERACIONAL GNU, 2014)

No software livre, a redistribuição de cópias, modificadas ou não, pode ser realizada gratuitamente ou mediante o pagamento de um preço estabelecido pelo prestador do serviço, denominado usuário, independentemente da anuência do proprietário. (O SISTEMA OPERACIONAL GNU, 2014)

\footnotetext{
17 Resolução INPI n. 54 (BRASIL, 2013) dispõe sobre os serviços de assistência técnica dispensados de averbação, consoante o disposto no art. 211 da Lei n. 9.279 (BRASIL, 1996).

18 "GNU is Not Unix": GNU não é Unix, para significar que Stallman, fundador do movimento, criou aplicativos, batizando o projeto de GNU para deixar claro que o novo sistema operacional, parecido com o UNIX, não era UNIX, não continha nenhum códigofonte Unix.
} 
O mesmo no caso de derivações, ao fazer modificações no software livre para uso próprio ou comercial, sem necessidade de mencionar a existência dos seus criadores. Se publicadas as modificações realizadas, não há obrigação de avisar ninguém em particular, ou de qualquer modo em particular. (O SISTEMA OPERACIONAL GNU, 2014)

A execução do programa de software livre pode ser feita por qualquer tipo de pessoa, em qualquer tipo de sistema computacional, ou para qualquer tipo de trabalho e propósito, sem que seja necessário comunicar ao desenvolvedor ou criador original qualquer outra entidade específica. (O SISTEMA OPERACIONAL GNU, 2014)

Para que as "liberdades essenciais" sejam exercidas, deve ser dado o acesso ao código-fonte do programa. Consequentemente, esse acesso ao código-fonte, é uma condição necessária da caracterização do software livre. (O SISTEMA OPERACIONAL GNU, 2014)

As licenças devem ser igualmente livres, permanentes e irrevogáveis. Todavia, certas regras sobre a maneira de distribuir o software são aceitáveis, quando elas não entrarem em conflito com as "liberdades essenciais". Por exemplo, o "copyleft" é a regra de redistribuição de um software livre, que não permite restrições que neguem as liberdades de outras pessoas. Essa regra não pode entrar em conflito com as "liberdades essenciais", porque ela as protege. (O SISTEMA OPERACIONAL GNU, 2014)

De uma maneira geral, esses termos se relacionam com o modelo de desenvolvimento e distribuição do software criado cooperativamente, cujos códigos de sistema ou de cada um dos programas, em lugar de constituir segredos, são postos à disposição dos usuários. (ARGUDO CARPIO, 2004)

O site do movimento esclarece que "software livre" não significa "não comercial": "[...] um programa livre deve estar disponível para uso comercial, desenvolvimento comercial e distribuição comercial". Também deixam claro que o desenvolvimento comercial de software livre é comum. Independentemente de ter havido o pagamento para obter cópias de software livre ou de ter acesso a elas sem custo, sempre há liberdade 
para o usuário copiar, mudar ou vender cópias do software. No projeto GNU se usa o copyleft para proteger convencionalmente essas "liberdades essenciais" para todos, embora não seja imprescindível. (O SISTEMA OPERACIONAL GNU, 2014)

Copyleft $e^{e}$ uma cláusula das licenças GPL ${ }^{19}$, idealizada para se contrapor a copyright, onde o autor declara compartilhar seus direitos, sem abrir mão da propriedade, autorizando a utilização, modificação e distribuição do software por outras pessoas, respeitados os termos específicos da licença. Um software livre sem copyleft pode ser transformado em não livre por um usuário, mas um software livre protegido por uma licença copyleft, se distribuído, deverá manter a mesma licença transmitindo os mesmos direitos. (SOFTWARE LIVRE, 2014). O licenciamento de software livre, assim, não configura disposição de bens, porque não há renúncia aos direitos autorais e a titularidade continua.

Cabe observar que a propriedade intelectual originária do autor do software livre, nesse contexto, se torna um condomínio com os chamados usuários, que passam a ser coproprietários, o mesmo ocorrendo com as derivações, que passam a ser copropriedade.

O código-fonte do software deverá ser revelado e, portanto, não de conhecimento exclusivo de seus autores e proprietários.

O site do movimento menciona que muitas das licenças de software livre são baseadas no copyright, devendo respeitar as "liberdades essenciais", deixando claro que se alguma licença de software livre baseada em contrato vier a impor restrições será inaceitável e não livre. (O SISTEMA OPERACIONAL GNU, 2014)

O acordo geral entre os usuários do software livre é o licenciamento através de uma licença de software livre. Os tipos de licença de software livre mais conhecidas são a GNU-GPL, GNU-AGPL, GNU-LGPL, GNU-FDL, MPL (Licença pública Mozilla), Licença Apache, Licença MIT e Licença BSD. (SOFTWARE LIVRE, 2014)

19 GPL: licença pública geral para programas da Free Software Foundation. 
O Projeto GNU esclarece também no seu site que outro grupo usa o termo "código aberto" ou "open source" com um significado parecido, mas não idêntico, ao de "software livre" porque este se refere às "liberdades essenciais" ao invés do preço, "livre" significa liberdade, a palavra “aberto” não. (O SISTEMA OPERACIONAL GNU, 2014)

A definição dos efeitos jurídicos do "software livre" decorre do consenso da comunidade do software livre relacionada em redes conectadas no ciberespaço, através da internet, pessoas muitas vezes não identificáveis, despersonalizadas, que ofertam bens e serviços às massas, geralmente desconhecidos como sujeitos de direitos no momento da constituição dos direitos obrigacionais.

Os participes da comunidade do software livre compartilham suas regras fundamentais denominadas "liberdades essenciais", incluindo a cláusula de compartilhamento obrigatório do código-fonte no contrato de adesão ao movimento e à comunidade, ainda que se possa considerar um único software livre.

Cabe esclarecer a natureza jurídica civil do acordo sobre as "liberdades essenciais", que inclui a cláusula de compartilhamento obrigatório do código-fonte, da essência do software livre, e das suas derivações também consideradas livres.

A natureza jurídica do software livre, um contrato atípico de adesão e de cláusulas que os integrantes do movimento consideram vinculantes, também chamado de "licença em rede" (FALCÃO et al., 2005), é contratual, principalmente a estipulação em favor de terceiros (FALCÃO et al., 2005), cumulada com oferta de condomínio, de permuta, de doação, de comodato.

A obrigação se estabelece unilateralmente, sem a necessidade da identificação de outra parte contratante para a sua validade. É suficiente que haja uma oferta de software declarado "livre".

Conforme o direito civil brasileiro, o que estipula em favor de terceiro pode exigir o cumprimento da obrigação, o compartilhamento das derivações como modificações e aperfeiçoamentos, uma espécie de licença cruzada. Ao terceiro, geralmente outro integrante da comunidade 
do software livre, em favor de quem se estipulou a obrigação, também é permitido exigi-la, ficando sujeito às condições e normas do contrato, quer dizer, ficará vinculado às "liberdades essenciais". (BRASIL, 2002, art. 436)

A comunidade do software livre, ou mesmo outro terceiro na condição de usuário do software livre, pode simplesmente aferir benefícios da utilização do software. Pode constituir uma vantagem para um sujeito indefinido, estranho ao desenvolvimento do software ofertado, que não necessita pagar um preço pelo bem e, ainda, pode auferir benefícios com a sua utilização e colher frutos, isto é, obter vantagens econômicas.

É, igualmente uma oferta de condomínio, porque cada condômino pode usar do software livre conforme sua destinação, sobre ele exercer todos os direitos compatíveis com a indivisão, inclusive reivindicar de terceiro, defender a sua posse e negociar a respectiva parte ideal, ou gravá-la. Observando, logicamente, as "liberdades essenciais" da comunidade. (BRASIL, 2002, art. 1.314.)

Ao considerar que o usuário de software livre deve ter exatamente os mesmos direitos que o seu autor, tratando-se de obra original ou derivada, o ponto de partida é que o software como objeto de direitos, desde o ponto de vista da "liberdade essencial", como bem imaterial que é, livremente utilizado por qualquer um, sem necessidade de qualquer autorização, torna igual o autor e o usuário. (CARRANZA TORRES, 2004)

O software livre pode ser caracterizado por oferta de permuta quando há uma troca de software originário presente por suas futuras derivações. (BRASIL, 2002, art. 533)

Uma oferta de doação quando permite futuramente a um terceiro, simplesmente, sem contraprestação, a execução do programa para qualquer propósito, ou seja, o uso gratuito. (BRASIL, 2002, art. 538-579)

$\mathrm{O}$ direito de autor no software livre, desde os seus fundamentos ideais, abarcando a liberdade de criação, a derivação e a circulação, é não exclusivo, é uma autolimitação privada de direitos.

Cabe observar que existe distinção entre "software livre" e "software aberto" ou de "código aberto". A Open Source Initiative define softwa- 
re aberto abrangendo as mesmas características do software livre da Free Software Foundation, de "liberdade essencial" do usuário, incluindo algumas restrições focadas no modelo corporativo e em negócios comerciais elaborados em torno do software. A diferença está no discurso e no público-alvo. O conjunto de licenças é semelhante, mas o software de código aberto não pode ser considerado um software livre. O fato de o programa estar com seu código aberto não garante sobre a sua distribuição, modificação e comercialização. Pode-se ter um programa com código aberto e a impossibilidade de derivações, contrariando o conceito de software livre. (OPEN SOURCE INITIATIVE, 2014)

As principais vantagens do software livre são: o compartilhamento de código-fonte, que pode simplificar o desenvolvimento de derivações, aperfeiçoamento e novas aplicações, a partir do software original; não ter custos de desenvolvimento para o usuário; ter um maior número de desenvolvedores com menos custos de produção e serviços; ampliar o número de usuários que podem competir utilizando um software sem incluir o preço de desenvolvimento (mais valia); por ter menor custo de produção e não ser exclusivo pode favorece o surgimento de pequenas empresas nos mercados locais.

A principal desvantagem jurídica do software livre se refere à responsabilidade civil e à segurança jurídica: é difícil, às vezes impossível, identificar quem é ou quem são autores do software ou das derivações, o mesmo quando se trata de encontrar o domicílio dos autores do software ou das derivações, para ações de responsabilidade; os autores das derivações não têm segurança jurídica, porque não há garantia de autoria de criação; e os usuários do software também não têm segurança jurídica, quer da autoria e domicílio dos autores do original ou das derivações, nem tampouco dos distribuidores. Quem de qualquer forma ou modo utiliza um software livre pode ser demandado se ele foi contrafeito e disponibilizado anarquicamente. Outra desvantagem é a falta de viabilidade econômica de uma propriedade não exclusiva e a qualidade de software desenvolvido com poucos recursos. 
Caso a disseminação do software livre tivesse sido totalmente exitosa, seria possível ter diminuído o ritmo da inovação no campo do softwa$r e$, o que não se verificou.

Por fim, cabe apontar alguns modelos de negócio baseados em software livre, em que a criação ou a apropriação de um software sem custo ou com custo baixo impulsiona a sua utilização: dos especialistas que desenvolvem softwares originais ou derivações de modo colaborativo, geralmente projetos universitários financiados com recursos públicos cujos órgãos financiadores não se importam com os resultados; das empresas que utilizam o software, aplicando ou executando programas de computador simples; dos prestadores de serviços de treinamentos e consultoria para utilização de software; dos distribuidores de software; dos prestadores de serviço de instalação, de interoperabilidade e de manutenção. (OPEN SOURCE INITIATIVE, 2014)

O "formato aberto" é uma especificação publicada para armazenar dados digitais, mantida geralmente por uma organização de padrões não proprietários, e livre de limitações legais no uso. Indica-se que pode ser implementável tanto em software proprietário como em software livre, usando as licenças típicas de cada um. O formato proprietário é desenvolvido, utilizado e comercializado segundo a política do titular dos direitos.

Os formatos abertos são um subconjunto do padrão aberto. O objetivo é garantir o acesso a longo prazo aos dados sem incertezas atuais ou futuras no que diz respeito aos direitos legais ou à especificação técnica. Um objetivo secundário dos formatos abertos é permitir a competição, em vez de permitir que o controle de um distribuidor sobre um formato proprietário iniba o uso de um produto de competição.

Para que um produto de software seja considerado como um "padrão aberto", ele deve atender a quatro fatores: 1) disponibilidade - as especificações do padrão devem estar publicamente acessíveis para qualquer pessoa ou organização que queria estudar ou implementar o padrão; 2) não possuir discriminação - padrões abertos não devem estabelecer nenhum critério de favorecimento ou discriminação por parte de seus implementadores; 3 ) extensibilidade - implementações de padrões abertos devem permitir extensões ou oferecer apenas um subset, se cabível; 4) sem 
royalties - para um padrão ser aberto, não devem ser cobrados royalties ou outras taxas para implementação e uso. O propósito da utilização de padrões abertos é facilitar a interoperabilidade entre aplicações e plataformas. (PACHECO, 2014)

A seguir serão tratadas as políticas públicas relacionadas à inovação e ao software livre.

\section{As Políticas Públicas de Inovação e Software Livre ${ }^{20}$}

Entende-se aqui por "políticas públicas" o estabelecimento de prioridades para as ações e, por efeito, as diretrizes das decisões de um governo para a solução de problemas sociais heterogêneos ou para a alocação de recursos públicos dentro de seu âmbito de competências visando o interesse público.

Observa-se, no Brasil, que o software livre foi uma das políticas adotada por segmentos dos governos federal e de alguns estados do Brasil, de forma bastante explícita desde o primeiro governo Lula, no campo das tecnologias de informação e processamento de dados. Paralelamente, os governos: federal e de alguns estados incentivam também, por meio da política industrial e de comércio exterior, um movimento forte e muito mais amplo pela inovação, cujos atores incentivam a proteção da propriedade intelectual para dar competitividade ao setor produtivo. Os movimentos do software livre e aberto tiveram e têm os seus espaços, mas não são os únicos.

No Brasil, entre as principais razões que motivaram o governo para impulsionar uma política de criação e utilização de software livre estavam: o custo relativamente alto do desenvolvimento de programas de computador para atender às necessidades do setor público; a falta de segurança na circulação de informações e armazenamento de dados do governo; a falta de autonomia e de capacidade tecnológica do país, para alcançar maior independência frente aos fornecedores de software do es-

\footnotetext{
20 Principais fontes consultadas: Branco (2004), Falcão et al. (2005), Falcão et al. (2007) e Carranza Torres (2004).
} 
trangeiro; a falta de massa crítica no setor; a falta de compartilhamento de conhecimento tecnológico. (BRANCO, 2004; FALCÃO, 2005)

No que se refere às necessidades de informatização, o país passou por um quadro bastante similar em dois extremos, no setor público, a administração pública; e no setor privado, as micro e pequenas empresas. Em comum está a necessidade de encontrar soluções para os problemas de operação de serviços cada vez mais massivos num país em crescimento, que vem demandando o armazenamento e a utilização de dados, informações e conhecimentos, alocando poucos recursos para P\&D.

Pode-se ampliar esse quadro e considerar o universo de instituições públicas e privadas, de empresas e de consumidores, cada vez mais ávidos por artefatos e soluções informatizadas e computadorizadas. Esse universo demandou, e ainda demanda, a criação e o incremento de soluções técnicas, tecnológicas e científicas, especialmente no que se refere a software e padrões informacionais.

Como bem se indagou, os problemas do setor público, há cerca de uma década fundamentalmente eram: Que tipo de software utilizar? Estimular a criação de novos softwares pela própria administração pública? Adquiri-los no mercado? Ao adquiri-los, exigir a abertura do código-fonte ou não? No caso de abertura, quem teria acesso a esse conhecimento? Somente a administração pública ou o público em geral? O software deveria ser contratado para um uso específico de um setor governamental específico, ou ele poderia vir a ter múltiplos usos por múltiplos setores da administração pública? (FALCÃO, 2005)

As respostas consubstanciaram algumas das políticas de informatização administrativa da administração pública. Mas passados mais de dez anos, parte do modelo está esgotado, teve um custo muito mais alto do que o previsto e precisa ser repensado. Não foram encontradas as solução para a macroeconomia brasileira, não se garantiu uma maior segurança para os dados e para as informações do governo, não se ampliou significativamente o processo de autonomia e capacidade tecnológica do país, nem se ampliou a independência de fornecedores e prestadores de serviços de empresas estrangeiras, nem se gerou um compartilhamento 
expressivo do conhecimento tecnológico dos softwares. Foi mais uma alternativa que propriamente uma solução.

No que se refere ao papel regulador do Estado (BRASIL, 1998, art. 174), o governo brasileiro impulsionou uma série de iniciativas para implementação do software livre, no intuito de racionalizar os gastos com programas de computador, como: o Decreto Presidencial de 2000, que criou, no âmbito do Conselho de Governo, o Comitê Executivo do Governo Eletrônico; o Decreto n. 29/2003, que instituiu o Comitê Técnico de Implementação de Software Livre; e a Instrução Normativa n. 4/2008, do Ministério do Planejamento, Orçamento e Gestão, incentivando a utilização de softwares disponíveis no Portal do Software Público. A intenção era que a administração pública somente adquirisse programas de computador com cláusulas de licenciamento que lhe permitissem usar, estudar o código fonte, copiar, modificar e redistribuir o programa a terceiros. (FIGUEIREDO E SILVA, 2013)

No mercado internacional, hoje, os softwares e padrões livres e abertos alavancam mais os negócios de grandes e médias do que das micro e pequenas empresas. Todavia, o mercado continua utilizando e preferindo as alternativas proprietárias mais eficazes, com melhores garantias e, geralmente, com menor custo final.

No Brasil foram cerca de dez anos de políticas de software livre num setor muito dinâmico, muito tempo sem que os problemas fossem solucionados por frutos das ações geradas pela política.

Nesse sentido, o governo precisa rever a sua política de compras e encomendas tecnológicas para o setor público e com recursos públicos. Atuando como contratante, comprando, criando ou difundindo softwares, ou como autoridade administrativa, que coordena recursos, normas e instituições públicas e privadas na consecução dos objetivos estratégicos. Ambos os caminhos devem ser percorridos em estrita consonância com os princípios e regras constitucionais. E observância do ordenamento jurídico, interno e internacional.

O governo não pode obrigar-se por lei a adquirir ou contratar software livre, aberto ou proprietário. Pode agir, como vem fazendo em mui- 
tos campos, fomentando e promovendo a inovação, a inclusão digital de empresas e consumidores, o crescimento da indústria, o avanço das técnicas, tecnologias e ciência da informação, a inviolabilidade de dados, informações e conhecimentos secretos, a neutralidade da internet.

Realiza-se, por fim, algumas observações sobre as políticas públicas no Brasil, relacionadas ao software: poder-se-ia ter avançado mais com a concentração da aplicação de recursos para desenvolver software proprietário, nos centros de $\mathrm{P} \& \mathrm{D}$ e nas empresas, considerando o avanço do livre comércio em escala mundial e o fato da rede de computadores não ter fronteiras; a política que estimula a licença gratuita de direitos e facilita o acesso ao código-fonte dissemina alguns conhecimentos, mas não garante o retorno do investimento e nem gera o aumento da receita das empresas nacionais que desenvolvem o software, embora isso facilite por algum tempo a prestação de serviços por aqueles que dominam o conhecimento no uso de software livre e aberto, não é uma boa ferramenta competitiva e nem favorece a segurança jurídica. Nesses casos, a propriedade intelectual deixou de ser um ativo intangível e uma vantagem na concorrência doméstica e internacional.

As empresas que absorvem software livre deixam ou diminuem o trabalho criativo, colocam menos bens no mercado, pagam menos impostos, contratam menos ou nenhum trabalhador, ao passo que muitos desenvolvedores de software livre não pagam impostos, geram pouco ou não geram empregos e, ainda, disponibilizam softwares, bases de dados, informações e até conhecimentos tecnológicos que são utilizados de melhor forma e beneficiam empresas no exterior. Algumas vezes, acabam fornecendo insumos em matéria de programas de computador e do pacote que é o software para médias e grandes empresas, muitas transnacionais, que poderiam pagar por isso. A política pública, assim, não estimulou a competitividade e nem a eficiência, nem cumpriu os ditames dos artigos 217 e 218 da Constituição Federal do Brasil.

No caso das empresas públicas, utilizar o software livre representa uma boa dose de vulnerabilidade, pois fica mais fácil para terceiros conhecer os mecanismos do sistema de funcionamento dos programas de computador, o que não compensa o investimento em pessoal e serviços 
para operar com programas de computador livre ou aberto. Conforme o dito popular: o barato muitas vezes pode sair caro. Pode significar a vulnerabilidade do sistema de segurança de dados e informações.

As políticas que dão preferência para a utilização de software livre, mesmo aberto, diminuem o incentivo à inovação e criam uma barreira ao comércio de licenças que geram a circulação de riquezas e o pagamento de impostos. Considerando o livre mercado, o incentivo e a preferência generalizada pelo software livre e aberto, podem gerar concorrência parasitária com o êxito de alguns empreendedores, com um efeito muito próximo ao dos subsídios ou vantagem desleal na concorrência quando financiado pelo governo. Acabam impedindo os desenvolvedores de software de buscarem soluções mais avançadas, mais eficientes, diminui muito o investimento no setor e acaba aumentando o custo das soluções.

Dois exemplos de inadequação das políticas de software livre podem ser apontados: um que recomenda a utilização de código aberto no processo eletrônico, artigo 14 da Lei n. 11.419/2006, que estabelecia a preferencia e priorizava a sua padronização; outro de contratação exclusiva de software livre no âmbito da administração pública do Estado do Rio Grande do Sul, Lei Estadual n. 11.871/2002, a seguir. (FIGUEIREDO E SILVA, 2013)

No caso da lei estadual (Lei n. 11.871/2002), ela foi suspensa pelo Supremo Federal do Brasil em 2004, cabendo resgatar alguns argumentos do Ministro relator:

A lei estadual fez uma declarada e antecipada preferência por um tipo de produto eletrônico, o software aberto ou completamente isento de restrições proprietárias; foi excepcionado o caráter isonômico da licitação para se substituir à Administração Pública na emissão de um prévio e superior juízo de prestimosidade de um determinado bem informático ante os demais concorrentes, que são concorrentes sabidamente numerosos e igualmente caracterizados por crescente sofisticação tecnológica de seus produtos; a lei mesma é que se encarregou de criar uma preferência e assim antecipar uma avaliação administrativa concreta ou empírica; avaliação traduzida na presunção de que um dado software satisfaz melhor aos 
interesses da Administração do que os outros; que o software de sua declarada preferência pode até ser o que melhor consulta aos interesses da Administração, em termos de preço, técnica e gradativa apropriação autóctone de uma tecnologia reconhecidamente de ponta, entre outras vantagens comparativas.

Indicando o Ministro relator: “[...] que todas as virtudes de um software somente podem ser aferidas no processo mesmo de certame em que a licitação consiste". (BRASIL, 2004)

Cabe observar, outrossim, que em muito casos de sistemas informáticos não é o custo da licença que mais impacta. Os custos mais significativos estão no hardware, na capacitação do pessoal, na instalação, operação, manutenção e outros serviços. Observa-se também que o fato dos softwares serem livres ou abertos não garante a interoperabilidade, tal é a diversidade de sistemas e programas que existem. O que demonstra que o custo da licença de software proprietário não é o principal problema.

No que se refere aos princípios da eficiência, conveniência e transparência do Direito Administrativo, não se pode pressupor que o software livre ou aberto será melhor, muitas vezes a orientação a um tipo de solução tecnológica faz com que ela se torne mais cara, sem representar necessariamente uma solução mais eficaz. O que contraria a neutralidade tecnológica.

O direcionamento da contratação de software livre na administração pública, em razão dos princípios da igualdade e da não discriminação dos operadores econômicos no mercado, pode se tornar uma questão muito delicada em razão da proibição de se mencionarem especificações técnicas no edital, salvo aquelas estritamente necessárias para a execução, cuja especificação, quando autorizada, sempre deverá estar acompanhada da expressão "ou equivalente".

Dentre os muitos programas criados especialmente para suprir as necessidades da atividade fim da administração pública, menciona-se o debate estabelecido entre o uso de software livre ou de software proprietário pelo governo, em razão das elevadas somas que envolviam esse tipo de contratação. Por se tratar de um método de serviço utilizando os pro- 
gramas de computador não foi de forma alguma uma contratação de baixo custo. (FIGUEIREDO E SILVA, 2013)

A diferença de um software livre para o software proprietário consiste fundamentalmente na difusão do código-fonte.

\section{Conclusão}

A utilização de software proprietário ou livre não é excludente, nem se pode obrigar por lei o setor público ou privado a optar por um ou por outro.

Os discursos dos movimentos do software livre e do open source prometem vantagens, porém, eles continuam coexistindo com o proprietário e com modelos "híbridos". Do ponto de vista dos governos, a escolha de produtos e serviços deverá ser feita caso por caso, facilitando o maior nível de competência e concorrência possível entre os fornecedores.

Os governos podem estimular o desenvolvimento de novas soluções tecnológicas, invento e criação de programas de computador e de padrões técnicos, também o seu incremento, mas os princípios que orientam as obrigações internacionais que estruturam o mercado global, bem como os princípios constitucionais dos estados nacionais, não permitem que os governos criem restrições comerciais, sob a forma de preferências por um modelo de negócio ou de tecnologia, e muito menos eliminando ou limitando os direitos de propriedade intelectual.

Nos estados nacionais, como o Brasil, em que a ordem econômica é fundada na valorização do trabalho humano e na livre iniciativa e balizada, entre outros, pelos princípios da propriedade privada, da função social da propriedade, da livre concorrência e da defesa do consumidor, o governo não pode obrigar o contratante a um regime que implique na renúncia ou limitação aos direitos decorrentes de sua criação. Deve, sim, cumprir os ditames constitucionais promovendo e incentivando o desenvolvimento científico, a pesquisa e a capacitação tecnológicas, ciente de que o conhecimento é um ativo intangível que integra o patrimônio dos 
agentes econômicos ou instituições públicas nacionais, portanto um indicador da riqueza do país.

\section{Referências}

ARGUDO CARPIO, E. Los derechos de propiedad intelectual y la protección del software. El software libre: significado, desafíos y oportunidades. Guadalajara, OMPI/JPI-JDA/GDL/04/T3 M, mar. 2004. ASCENSÃO, J. de O. Direito autoral. 2. ed. Rio de Janeiro: Renovar, 1997.

BOBBIO, N.; Matteucci, N.; Pasquino, G. Il Dizionario di politica. Turino: UTET, 2004.

BRANCO, M. D. Software livre na administração pública brasileira. 21/09/2004, versão digital. 2004.

BRASIL. Constituição (1988). Constituição da República Federativa do Brasil. 1988.

BRASIL. Decreto n. 1.335, de 30 de dezembro de 1994. Promulga a ata final que incorpora os resultados da Rodada Uruguai de Negociações Comerciais Multilaterais do GATT.

BRASIL. Decreto n. 29/2003, que instituiu o Comitê Técnico de Implementação de Software Livre. 2003.

BRASIL. Decreto n. 75.572, de 8 de abril de 1975. Promulga a Convenção de Paris para a Proteção da Propriedade Industrial, Revisão de Estocolmo, 1967.

BRASIL. Decreto n. 75.699, de 6 de maio de 1975. Promulga a Convenção de Berna para a Proteção das Obras Literárias e Artísticas de 1886, revisão de Paris em 1971.

BRASIL. Decreto Presidencial de 2000, que criou o Comitê Executivo do Governo Eletrônico. 2000.

BRASIL. Instrução Normativa n. 4/2008, do Ministério do Planejamento, Orçamento e Gestão. 2008. 
BRASIL. Lei n. 10.406, de 10 de janeiro de 2002. Institui o Código Civil. 2002.

BRASIL. Lei n. 11.419, de 19 de dezembro de 2006. Dispõe sobre a informatização do processo judicial; altera a Lei n. 5.869, de 11 de janeiro de 1973 - Código de Processo Civil; e dá outras providências. 2006.

BRASIL. Lei n. 9.609, de 19 de fevereiro de 1998. Dispõe sobre a proteção de propriedade intelectual de programa de computador, sua comercialização no país e dá outras providências. 1998.

BRASIL. Lei n. 9.610, de 19 de fevereiro de 1998. Altera, atualiza e consolida a legislação sobre direitos autorais e dá outras providências. 1998.

BRASIL. RS. Lei Estadual n. 11.871, de 19 de dezembro de 2002.

Dispõe sobre a utilização de programas de computador no Estado do Rio Grande do Sul. 2002.

BRASIL. Supremo Tribunal Federal. Plenário. ADI 3059 MC/RS - RIO GRANDE DO SUL, 15/04/2004. 15/04/2004, Medida Cautelar na Ação Direta de Inconstitucionalidade, relator Ministro Carlos Ayres Britto. 2004.

BRASIL. Tribunal de Contas da União. Plenário AC-1521-39/03-P.

Relator: Augusto Sherman. Proc. 003.789/1999-3. 08/10/2003.

BUENO, N. Conceitos e discussão sobre software livre, software aberto e software proprietário. In: OKADA, A. (Ed.). Open educational resources and social networks: Co-Learning and Professional Development. London: Scholio Educational Research \& Publishing, 2012.

CARRANZA TORRES, M. Problemática jurídica del software libre. Buenos Aires: Lexis Nexis, 2004.

CARVALHO, N. P. A estrutura dos sistemas de patentes e de marcas: passado, presente e futuro. Rio de Janeiro: Lumen Juris, 2009. 
CORREA, C. M. Acuerdo TRIPs: regimen internacional de la propiedad intelectual. Buenos Aires: Ciudad Argentina, 1996.

DRAHOS, P. F. A philosophy of intellectual property. Dartmouth: Aldershot, 1996.

FALCAO, J. Direito do software e a administração pública. Rio de Janeiro: Lumen Juris, 2007.

FALCAO, J. et al. Estudo sobre o software livre. Comissionado pelo Instituto Nacional da Tecnologia da Informação (ITI). Rio de Janeiro: FGVRJ, 2005.

FERREIRA, A. B. de H. Dicionário Aurélio da Língua Portuguesa. 5. ed. Curitiba: Positivo, 2010.

FIGUEIREDO E SILVA, C. E. R. de. Propriedade intelectual de programa de computador desenvolvido para utilização na administração pública: estudo de caso. Tese de doutorado. Florianópolis: UFSC, 2013.

GOMES, O. et al. A proteção jurídica do software. Rio de Janeiro: Forense, 1985.

MERGES, R. P. Who owns the Charles River Bridge? Intellectual property and competition in the software industry. University of California at Berkeley School of Law Public Law and Legal Theory Working Paper, n. 15, Oct. 1999.

O SISTEMA OPERACIONAL GNU. O que é o software livre? A definição de software livre. [2014]. Disponível em: <http://www.gnu.org/ philosophy/free-sw.pt-br.html>. Acesso em: 30 jan. 2014.

ONU. Organização das Nações Unidas. Declaração Universal dos Direitos Humanos. Resolução 217 A (III) da Assembleia Geral das Nações Unidas, em 10 de dezembro de 1948.

OPEN SOURCE INITIATIVE. The Open Source Initiative. [2014]. Disponível em: <http://opensource.org/>. Acesso em: 30 mar. 2014. 
PACHECO, G. Guia ODF, um documento de referência de migração para formatos abertos. Revista Espírito Livre, on-line, 15 de novembro de 2013. Disponível em: $<$ http://www.revista.espiritolivre.org/guia-odf-umdocumento-de-referencia-de-migracao-para-formatos-abertos $>$. Acesso em: 30 jan. 2014.

PIMENTEL, L. O. (Org.). Proteção jurídica de software. APL/SC/ Tecnologia da informação e comunicação. Florianópolis: IEL, 2008.

PIMENTEL, L. O. O acordo sobre os direitos de propriedade intelectual relacionados com o comercio. Seqüência: Estudos Jurídicos e Políticos, Florianópolis, a. XXIII, n. 44, jul., 2002.

PIMENTEL, L. O.; AREAS, P de O. Manual básico de contratos de software. APL/SC/Tecnologia da informação e comunicação. Florianópolis: IEL, 2008.

PIMENTEL, L. O.; CAVALCANTE, M. D. A proteção jurídica dos programas de computador. In: CORAL, E.; PEREIRA, V. A.; BIZZOTTO, C. E. N. Tecnologia da informação e comunicação. Florianópolis: IEL, 2007.

SAMUELSON, P. et al. A manifesto concerning the legal protection of computer program. Columbia Law Review, USA, v. 94, p. 2.308-2.431, 1994.

SANTOS, M. J. P. A proteção autoral de programas de computador. Rio de Janeiro: Lumen Juris, 2008.

SHEMTOV, N.; WALDEN, I. (Ed.). Free and open source software: policy, law and practice. Oxford University Press, USA, 2014.

SILVA, De P. e. Vocabulário jurídico. ed. 30. Rio de Janeiro: Forense, 2013.

SOFTWARE LIVRE. [2014]. Disponível em: <http://pt.wikipedia.org/ wiki/Software_livre $>$. Acesso em: 30 jan. 2014.

STALLMAN, R. M. Free software, free society: selected essays of Richard M. Stallman. Boston: GNU Press, 2002. 
UNCTAD. Free and open source software: policy and development implications. TD/B/COM.3/EM.21/2 17, Aug. 2004.

WIPO. Intellectual property handbook: policy, law and use. N. 489 (E). Chapter 7: Technological and legal developments in intellectual property; computer programs. 2.ed. Reprinted. Geneva: WIPO, 2008.

WIPO. Tratado de Direitos Autorais da OMPI (WCT). 1996.

ZIBETTI, F. W. Relação entre normalização técnica e propriedade intelectual no ordenamento jurídico do comércio internacional. Tese de doutorado. São Paulo: USP, 2012.

ZITTRAIN, J. Normative principles for evaluating free and proprietary software. Harvard Law School Public Law, Research Paper, n. 98. 71 U. Chi. L. Rev. 265, 2004.

Luiz Otávio Pimentel é Doutor em Direito; professor permanente e Coordenador do Programa de Pós-Graduação em Direito (PPGD), professor do Programa de Pós-Graduação em Engenharia e Gestão do Conhecimento (PPGEGC), líder do Grupo de Pesquisa em Propriedade Intelectual, Transferência de Tecnologia e Inovação (PITTI), da Universidade Federal de Santa Catarina (UFSC); professor colaborador do Programa de Pós-Graduação em Propriedade Intelectual e inovação do Instituto Nacional da Propriedade Industrial (INPI). E-mail: pimentel@matrix.com.br.

Endereço profissional: PPGD, CCJ, UFSC, Campus Universitário, s/n, Trindade, Caixa Postal 476, CEP: 88040-900, Florianópolis, SC.

Cláudio Eduardo Regis de Figueiredo e Silva é Doutor em Direito; juiz de Direito no Estado de Santa Catarina; Diretor Geral da Escola Superior da Magistratura do Estado de Santa Catarina (ESMESC) e professor da Academia Judicial do Tribunal de Justiça de Santa Catarina (TJSC). E-mail: claudioregisdefigueiredo@ gmail.com.

Endereço profissional: ESMESC, Rua dos Bambus, 116, Itacorubi, CEP: 88034570 Florianópolis, SC. 